\title{
ENSINO DE FILOSOFIA E EJA: contextualização histórica e desafios da contemporaneidade
}

\author{
L. R. A. dos Santos, P. C. de M. Chagas
}

Instituto Federal do Rio Grande do Norte - Campus Macau

luiz.santos@ifrn.edu.br - patricia.chagas@ifrn.edu.br

Artigo submetido em agosto/2011 e aceito em setembro/2011

\section{RESUMO}

O labor apresentado aqui pretende discutir o intercurso histórico e conceitual da Educação de Jovens e Adultos - EJA - e a disciplina de Filosofia nesse contexto de situação. Nesse sentido, o trabalho fez uma contextualização histórica destas duas realidades distintas e a apreciação de documentos originais que tratam da referida modalidade de oferta de ensino. Em seguida, realizou-se uma atividade empírica com 79 alunos da modalidade EJA do IFRN campus Macau, que responderam a um questionário sobre a percepção e expectativas do ensino de Filosofia. O IFRN tem gerado um quadro de qualificação, de natureza profissional e humanística, que certamente está contribuindo para o crescimento socioeconômico da microrregião salineira. Nesse contexto, os conteúdos inerentes à disciplina de Filosofia têm sido essenciais à concretização dos valores agenciados pela Educação. Tais valores se referem principalmente ao desenvolvimento de um sentimento de cidadania que ultrapasse a mera formalização legal. Ademais, foi feito um levantamento bibliográfico para consubstanciar teoricamente todas as intuições primeiras, à luz de Aranha e Martins (1998, 2009), Cortela (2006), Paiva (2003), Paiva (2005) e Pinsky (2005).

PALAVRAS-CHAVE: ensino de filosofia, EJA, cidadania, liberdade.

\section{TEACHING OF PHISOPHY AND EJA: historical contextualization and challenges of the present} times

\section{ABSTRACT}

The work presented here discusses the historical and conceptual intercourse of the Youth and Adult Education - EJA - in Brazil within the discipline of Philosophy in this context of situation. In this sense, this work has made a historical contextualization of these two distinct realities as well as the appreciation of original documents that deal with this kind of educational offerings. An empirical activity with 79 Youth and Adult Educational students from the 'Campus IFRN Macau' was made. The students answered a questionnaire about the perception and expectations related to the Teaching of Philosophy. It is important to say that IFRN has generated a framework of qualifications, professional and humanistic in nature, and is certainly contributing to the socioeconomic growth of the micro-region called 'Salineira' in Rio Grande do Norte. We understand that the content linked to the discipline of Philosophy has been essential to the achievement of values addressed by Education. These values have to do, primarily, to the development of a sense of citizenship that goes beyond mere legalization. In addition, we made a bibliographic review up from scholars like Aranha and Martins (1998, 2009), Cortela (2006), Paiva (2003), Paiva (2005) and Pinsky (2005) in order to substantiate, theoretically, all beforehand intuitions.

KEY-WORDS: philosophy teaching, EJA, citizenship, freedom. 


\title{
ENSINO DE FILOSOFIA E EJA: contextualização histórica e desafios da contemporaneidade
}

\section{INTRODUÇÃO}

\begin{abstract}
"Acho que na sociedade atual nos falta filosofia. Filosofia como espaço, lugar, método de reflexão, que pode não ter um objetivo determinado, como a ciência, que avança para satisfazer objetivos. Faltanos reflexão, pensar, precisamos do trabalho de pensar, e parece-me que, sem idéias, não vamos a parte nenhuma".
\end{abstract}

José Saramago

A Educação de Jovens e Adultos, compreendida em sua abrangência conceitual como campo social de práticas educativas, apresenta na sua configuração um processo histórico marcado pela vulnerabilidade, descontinuidade e diversidade de trajetórias pessoais e sociais dos sujeitos pertencentes a esse campo.

Essas marcas históricas revelam expressões e facetas da complexidade humana denominadas por Arroyo (2007) de "trajetórias e identidades coletivas", que nos apontam histórias de vida similares, histórias de uma coletividade, protagonizadas por sujeitos concretos, que se multiplicam e se entrecruzam em seus enredos, roteiros e papéis sociais, uma vez que "desde que a EJA é EJA esses jovens e adultos são os mesmos: pobres, desempregados, na economia informal, negros, nos limites da sobrevivência. São jovens e adultos populares" (ARROYO, 2007, p. 29).

O reconhecimento da identidade coletiva desses jovens e adultos vem nos instigando, como docentes, sobre as possibilidades, sobretudo educacionais e culturais de, na contrapartida das trajetórias de insucessos pessoais e coletivos, construir novas reflexões e práticas educativas na perspectiva de ressignificar o que é vulnerável, descontínuo e diverso, contrapondo-nos a uma ótica pessimista de negação, de negatividade, de imagens estereotipadas, de discursos instaurados, ora sob comiseração e vitimização, ora sob derrotismo dos sujeitos em questão.

Tendo em vista a realidade aqui apontada, acredita-se que a relevância do trabalho proposto aqui se dá por seu ineditismo, uma vez que apesar da proximidade entre as anseios envoltos na proposta da disciplina de Filosofia no ensino médio, junto as aspirações presentes na Educação de Jovens e Adultos - EJA - não havia trabalhos que relacionassem esses dois campos. As demandas próprias da sociedade contemporânea, no que se refere a educação como mola propulsora da cidadania, são diversas e bastantes díspares. Se exige que a educação perpasse aspectos tais como o trabalho, a técnica, a cultura, a ciência. Consentindo que o educando participe ativamente da sociedade na qual está inserido. Logo, o papel da Filosofia é bastante discutido quanto a sua conveniência ou não, na medida em que se espera que funcione como ferramenta de inserção social. 
Como a obrigatoriedade da Filosofia no ensino médio é recente, ainda não existem trabalhos que sirvam de parâmetro e, ao mesmo tempo, norteiem o trabalho docente. Sobremaneira, com os alunos do PROEJA, para os quais não existe metodologia específica aos conteúdos de Filosofia. Nesse sentido, devemos entender que a educação de jovens e adultos no Brasil, pretende contribuir para a formação de uma identidade nacional mais forte. Identidade que não se imiscua em assuntos que apequenem a autonomia do indivíduo frente as vicissitudes da cotidianidade, e conjuntamente a isso permita que este se entenda como partícipe de uma coletividade.

Correia (2009), afirma que a Filosofia é uma produção comunitária, de toda sociedade, já que humaniza as pessoas. Diante deste fato, se arrola perfeitamente aos fins da Educação de Jovens e Adultos que serão devidamente apontados.

Quanto aos objetivos almejados o trabalho aqui apresentado visa discutir o intercurso histórico e conceitual da Educação de Jovens e Adultos e a disciplina de Filosofia nesse contexto de situação. Especificamente, se objetivou: contextualizar historicamente a EJA e o ensino de Filosofia no Brasil; apresentar as propostas tanto da EJA quanto da Filosofia em prol da construção do sentimento de cidadania no indivíduo; expor as inquietações que o ensino de Filosofia na EJA sugere no que tange ao desenvolvimento de liberdades substantivas, por meio do ato de refletir; fazer uma análise das expectativas dos alunos da EJA no que se refere a matéria de Filosofia na sua formação.

\section{O PROCESSO HISTÓRICO DA EDUCAÇÃO DE JOVENS E ADULTOS}

Não é possível compreender a educação de jovens adultos no Brasil sem fazer referencia ao período colonial. Pode até parecer anacrônico tentar fazer elucubrações como estas sobre um contexto histórico totalmente diferente. Contudo, apesar de todas as ressalvas, não se pode furtar ao dever de tentar compreender, mesmo que superficialmente, as distintas políticas de educação popular que existiram desde o nascimento do Brasil.

Antes de qualquer assertiva é lúcido perceber que a prática da educação popular, nos tempos do Brasil colônia, não era uma realidade tal qual nos moldes atuais, ou seja, uma formação no sentido de construir o acesso ao que se concebe hoje como um desenvolvimento pleno da cidadania. Mas é a partir de tal movimento que se principiou originalmente o sistema educacional brasileiro.

Assim sendo, de acordo com Silva (2007), o início a educação de adultos no Brasil se deu com a chegada da Companhia de Jesus, ainda no século XVI. Destarte, a educação de adultos, em seus primórdios, tinha como intuito primordial catequizar os índios encontrados, ensinando-os os costumes e princípios da religião cristã.

Como destaque é viável afirmar que dificilmente esta incidia sobre o domínio da escrita e leitura. Nesse sentido, apenas possibilitava uma certa familiarização para aqueles que estavam sendo catequizados com algum tipo de instrumentalização básica, necessária ao convívio com os colonos e a prática dos costumes cristãos. Nesse sentido, é possível inferir que o intento da educação, no Brasil colônia, e até por volta do século XVIII era domesticar os 
indígenas, bem como a população escrava negra, que chegava da África. Não tendo finalidade alguma de ajudar na formação qualquer tipo de autonomia no indivíduo, até mesmo porque boa parte da corte portuguesa também era composta por analfabetos (PAIVA, 2003).

Com a chegada da família real ao Brasil, no início co século XIX, e, portanto, devido as necessidades demandadas pela corte portuguesa, de uma formação mais compatível com o perfil da classe que acabará de chegar, o sistema de ensino brasileiro melhorou, ao ser comparado com o que existia antes. Contudo, o processo educacional insipiente à época era caracterizado por ser mormente voltado para as elites (PAIVA, 2003).

Mas, em 1827, acorde Paiva (2003), com o denominado projeto Stockler se pretendeu dar um aporte considerável a instrução popular. Em uma tentativa de compensar as localidades mais populosas, nas quais existiriam escolas elementares, para o ensino das primeiras letras. A despeito da relevância de tal projeto, ele fracassou por conta, entre outros aspectos, da precarização dos ordenados pagos aos professores.

Entretanto, é fácil observar que alguma herança resultou da política mal sucedida do projeto de 1827, uma vez que algumas escolas permaneceram em funcionamento, contribuindo para a instrução popular. Só que em 1834, com um Ato Adicional, o Império se desencarregou de seu papel central na manutenção da instrução pública, na medida em que deixava para as províncias tal responsabilidade. Como estas últimas não tinham condições de manter a qualidade requerida em tal empreitada, se agudizou mais ainda o hiato existente entre a educação das elites, na corte, e a instrução das populações mais carentes.

É fato que no ínterim entre o Ato Adicional de 1834 e o final do século XIX houveram ainda outros projetos que tinham por intuito discutir a educação popular, até mesmo em uma perspectiva profissionalizante. Não obstante, tais discussões invariavelmente não saíram do papel, não se transformaram em políticas públicas de Estado. Principalmente, em função do famigerado Ato que deixava a responsabilidade da educação pública por conta das províncias, sem que estas tivessem obrigatoriedade alguma de prestar contas de suas ações. Logo, aquelas mais favorecidas do ponto de vista do desenvolvimento econômico obtiveram resultados melhores do que outras, não tão afortunadas (PAIVA, 2003).

Chegado o final do século XIX e início do XX, com o estímulo a imigração estrangeira, da mesma forma que com o desenvolvimento de novos segmentos da economia nacional. Surgem, necessariamente, novas demandas de mão-de-obra. Ponto este que está intimamente relacionado a instrução popular. Todavia, na medida em que uma enorme parcela da população era composta ainda por analfabetos, surge uma problemática nova, em função da incapacidade da maior parte das pessoas se adequarem as necessidades do mercado. Já em 1882, Rui Barbosa, ao ser relator de um parecer-projeto sobre a reforma Leôncio de Carvalho, entendia que existe uma conexão intima entre a educação e o desenvolvimento de um pais (PAIVA, 2003). Percebe-se, desta forma, que já existia por parte da elite política nacional, ainda no período do Império, o entendimento de que deveriam ter lugar políticas efetivas voltadas para instrução da massa da população brasileira.

Com o advento do nacionalismo brasileiro, já enviesado no século XIX, mas que se tornou latente quando da Primeira Guerra mundial, discursos inflamados foram proclamados em prol do desenvolvimento do país. Todos tinham por mote principal a necessidade de se 
instilar o desenvolvimento da nação, por meio de padrões mínimos de instrução. Destarte, em 1925, o decreto n`16.782-A tinha apreço por "todos os graus de ensino", desde o infantil até o adulto. Mas deve-se lembrar da não dotação orçamental prevista para as medidas pretendidas (PAIVA, 2003). Logo, o Brasil possuía um razoável programa de educação universal apenas no papel, haja vista as constrições orçamentárias que impediam o real progresso do mesmo.

Em 1932, é lançado o Manifesto dos Pioneiros da Educação Nova (BRASIL,2010), que almejava uma solução para o problema da educação no Brasil, de forma científica e ampla, no qual as idiossincrasias regionais fossem respeitadas, resguardando-se os pré-requisitos de que a educação seria pública, laica, gratuita e de qualidade. Mas, outra vez, por motivos políticos não ocorreram as mudanças necessárias, a não ser em alguns Estados, onde houve a intervenção real de alguns personagens que se colocaram a frente do processo (PAIVA, 2003).

Em 1942, foi criado o FNEP - Fundo Nacional para o Ensino Primário, o qual só foi efetivamente posto em funcionamento em 1943, com o FNEP, finalmente a peleja entre os Estados da federação e a União por fomento à educação é resolvida, na medida em que a união assumiu sua responsabilidade no tocante a construção de escolas e qualificação técnica das pessoas envolvidas (PAIVA, 2003). Entretanto, só em 1945 pode-se afirmar que a educação de adultos foi realmente desvinculada da educação elementar, uma vez que uma parcela dos recursos (25\%) destinados a educação básica foram destinados a educação de adolescentes e adultos (PAIVA, 2003).

Pode-se indicar ainda como marcos da educação de adultos no Brasil, a Campanha Nacional da Educação de Adolescentes e Adultos, criada em 1946, impulsionada pelo Ministério da Educação e Saúde (MES). Houve também a Campanha de Educação Rural, de 1952. O $2^{\circ}$ Congresso Nacional da Educação de Adultos, ocorrido em 1958. A Mobilização Nacional da Erradicação do Analfabetismo, de 1957. Todos foram movimentos que eram provenientes do governo federal. Portanto, podem perfeitamente serem abarcados no rol das políticas públicas de educação de adultos. Políticas que de fato não tiveram a continuidade que deveriam ter, ou mesmo, que tiveram problemas metodológicos ou conceituais que impossibilitaram que alcançassem os objetivos a que se propunham.

\subsection{EDUCANDO PARA A DEMOCRACIA}

O foco na educação é condição indispensável ao desenvolvimento sócio-político de qualquer país. Sendo assim, tanto Anísio Teixeira (apud PAIVA, 2005), quanto Paulo Freire (2003) deixaram claro que a educação não é privilégio de alguns, em uma sociedade eminentemente aristocrática, mas sim pré-requisito necessário ao desenvolvimento da democracia.

Levando em consideração que esta cria possibilidades de liberdade para a vida em sociedade. A qualidade nos saberes obtidos por meio da cultura letrada é considerada pelos teóricos citados um direito de todos, sem que se abra exceção para qualquer critério de ordem etária, a educação de qualidade deve resguardar sobretudo os princípios democráticos, os quais são a antítese de uma mencionada visão aristocrática, que privilegia a formação de classes sociais desiguais, as quais uns tem acesso as benesses econômicas e 
sociais, ao passo que outros deveriam meramente regozijarem-se à posição de meros coadjuvantes submissos daqueles que sabem ditar os rumos sociais.

Por meio das concepção de educação de qualidade como guarda dos princípios democráticos, fica patente que a educação deve ser mola propulsora do desenvolvimento da cidadania plena, conforme interpretação da abordagem de Anísio Teixeira, elaborada por Paiva (2005), afirmando que o primeiro tencionava uma educação que conduzisse a formação do cidadão irrestrita, que não se circunscreva a alguns anos de educação formal, mas em uma continuidade e sistematicidade que abarquem o direito de aprender por toda a vida do indivíduo.

Entende-se que ao se tratar de educação democrática, não é permitido fazer restrições conceituais quanto a classe, gênero, etnia ou faixa etária, sem perder o sentido lato do termo, que por si só dá vazão a um cem número de aproximações às mais diversas peculiaridades sociais e culturais inerentes as sociedades contemporâneas. Porquanto a etimologia da palavra educação refere-se a conduzir para fora, logo, em preparar o indivíduo para o mundo. Tarefa esta que de forma alguma pode-se considerar completa em fase alguma da vida de um indivíduo.

A Declaração de Hamburgo (UNESCO, 1999) datada de 1997, estabelece diversos objetivos que devem ser não só almejados, mas alcançados no âmbito da educação adultos. Objetivos tais quais os que foram expostos anteriormente. O modelo brasileiro de Educação de Jovens e Adultos se fundamenta na citada declaração a titulo de criar alicerces sólidos para os programas que estão sendo desenvolvidos no Brasil, porquanto o tema principal de qualquer modalidade de educação é fazer com que as pessoas participem vigorosamente da vida de suas sociedades, em todos os aspectos possíveis ao ser humano. Permitindo que suas escolhas sejam pautadas por critérios que levem em consideração a autonomia, a liberdade e a responsabilidade, em seus caracteres individuais e coletivos.

Ademais, ainda segundo a Declaração de Hamburgo, a educação de adultos deve levar em consideração o patrimônio cultural comum, partilhado pelo homens e mulheres de cada comunidade. Nesse sentido, todas as vivências de cada comunidade devem ser respeitadas e estimuladas na formação de jovens e adultos. Por conseguinte, as comunidades atingidas pela educação de adultos estarão mais aptas a lidar com as transformações inerentes à dinâmica social, permitindo com que as pessoas convivam de modo mais harmônico, sem perder a capacidade crítica no enfrentamento das vicissitudes cotidianas (UNESCO, 1999).

Segundo o PNAD/IBGE, no ano de 2009, o número de brasileiros, com idade igual ou superior a 10 anos, que possuíam 11 anos ou mais de estudo subiu a um patamar de $33 \%$ (53,8 milhões) da população, quando comparado aos $25,9 \%$ (38,7 milhões) de 2004 . Isso quer dizer que uma parcela maior da população brasileira tinha concluído o ensino médio. Contudo, os números acima, apesar de serem benfazejos em uma certa ótica, não mostram toda a realidade, já que o mesmo estudo menciona que a media nacional, para pessoas na mesma faixa etária, é de 7,2 anos de estudo. Ou seja, a média no Brasil é que as pessoas não tenham concluído sequer o nível fundamental de instrução.

Juntos aos dados elencados acima também é importante lembrar que o número de pessoas com menos de 4 anos de estudo sofreu um decréscimo de 25,9\% (38,7 milhões de 
pessoas) para 22,2\% (36,2 milhões). Nesse sentido, mesmo que os números mostrem que o quadro nacional está melhorando no quesito educação, ainda não existem motivos para comemorar, porque uma parcela significante da população, mais de 20 milhões de pessoas, é destituída de escolaridade básica. Fato este que compromete profundamente o pleno desenvolvimento humano e social destas pessoas.

No censo de 2010 a população brasileira foi estimada em 190.755,799 pessoas, das quais $144.823,504$ encontravam-se na faixa etária acima dos 15 anos de idade, o que representa um percentual de $75,9 \%$ da população. Em um mundo ideal seria necessário que todos os indivíduos acima de 15 anos tivessem pelo menos iniciado o ensino médio. Entretanto, o que chama a atenção é o fato de que, independente de uma enorme parcela da população brasileira acima dos 18 anos não ter terminado o ensino médio, fato que por si só já chama atenção. Em 2010, apenas metade daqueles que estavam entre 15 e 17 anos, ou mais precisamente, $50,9 \%$ da população dessa faixa etária se encontrava no ensino médio, ou seja, estão fora do nível adequado (BRASIL, 2010). Logo, de uma maneira ou outra, são sujeitos que potencialmente se enquadram na Educação de Jovens e Adultos.

Diante dos números levantados é patente a dificuldade pela qual passa a educação brasileira, no que se refere especificamente a manter os indivíduos no nível adequado de educação escolar. Fator que pode ter repercussão em toda a vida adulta das pessoas, seja no fator desenvolvimento pessoal ou no acesso ao mercado de trabalho. Sabe-se também que este não é um problema recente, já que existe desde os primórdios da história brasileira.

\subsection{A EDUCAÇÃO DE JOVENS E ADULTOS CONSOLIDADA COMO MODALIDADE DE ENSINO}

Nenhuma das políticas aventadas anteriormente pôde ter um raio de alcance tão extenso e dotação orçamentária quanto o atual PROEJA. Transformando este realmente em uma política de Estado. O próprio documento base do Programa Nacional de Integração da Educação Profissional com a Educação Básica na Modalidade de Educação de Jovens e Adultos (BRASIL, 2007), assevera que apenas a partir do ano de 2003, por meio do programa Brasil Alfabetizado tais práticas começaram a se consubstanciar verdadeiramente no âmbito nacional.

Dentre diversas outras propostas do PROEJA, destaca-se a de fomentar a integração entre trabalho, ciência, técnica, tecnologia, humanismo e cultura geral na formação do indivíduo que se encontre no campo da Educação de Jovens e Adultos (BRASIL, 2007). É de suma importância que os objetivos mencionados sejam buscados conjuntamente em qualquer modalidade de educação. É facultado observar que esta se torna uma pretensão um tanto quanto audaciosa. Pode ser denominada assim precisamente porque a sociedade organizada, como um todo, ainda não desenvolveu suficientemente a discussão, assim como o intercâmbio conceitual e prático necessário à interpolação real destas distintas áreas na construção do sentimento de cidadania.

O que outrora era tomado como resultado indubitável da educação percebe-se hoje como uma construção social, que não é apenas uma conseqüência tácita de práticas intuitivas. Portanto, o fomento ao intercâmbio entre os diversos campos de atuação humano 
elencados, tem a prioridade de ser buscado como condição suficiente e necessária ao desenvolvimento humano não parcial, mas completo.

Como fator objetivo, o documento mencionado também deixa claro que nunca houve uma continuidade no que tange a educação de jovens e adultos no Brasil. Pois todos os projetos e programas que ocorreram tiveram seu lugar em ações de pouca repercussão social, que não se tornaram políticas públicas de fato (BRASIL, 2007).

Entende-se também que na situação pela qual passa a formação da mão-de-obra no país, a mera formação escolar não é capaz de acompanhar as diversas necessidades apresentadas pela sociedade, sendo assim, faz-se necessária uma educação acompanhada de formação profissional, que leve em consideração a trajetória escolar intermitente dos jovens e adultos atingidos por tais programas (BRASIL, 2007).

Segundo o parecer do relator Carlos Alberto Jamil Cury, datado de maio de 2000, a Lei 9.394/96 deixa claro que a EJA é "uma modalidade da educação básica nas etapas do ensino fundamental e médio, usufrui de uma especificidade própria que, como tal deveria receber um tratamento conseqüente" (BRASIL, 2000). O mesmo parecer assevera ainda que devido a diversidade de habilidades exigidas na contemporaneidade, seja no âmbito do trabalho ou do convívio social, é mais que necessário o acesso a uma gama infindável de saberes disponíveis, haja vista que tais habilidades incidem diretamente nas relações de trabalho e sócio-políticoculturais, oportunizando desta forma a possibilidade de o indivíduo inserir-se de forma plena na sociedade.

A EJA tem certas particularidades patentes, em função das características próprias dos segmentos populacionais ao qual se destina. Portanto, deve ter um modelo pedagógico próprio, que cumpra amplamente seu papel na formação de jovens e adultos, a saber: equalizar as disparidades sócio-educacionais que foram criadas durante o transcorrer da vida destas pessoas (BRASIL, 2000). Porque, segundo o documento citado, "a eqüidade é a forma pela qual se distribuem os bens sociais de modo a garantir uma redistribuição e alocação em vista de mais igualdade, consideradas as situações específicas" (BRASIL, 2000, p.10). Por conseguinte, a EJA deve objetivar potencializar as capacidades individuais necessárias a fazer com que o aluno tocado por essas políticas educacionais possa se desenvolver enquanto cidadão, perfazendo assim uma sociedade mais igualitária.

A EJA tem entre suas funções atualizar os conhecimentos adquiridos para toda a vida, qualificando as pessoas a terem maior domínio da realidade na qual estão inseridas, pois o ser humano é por excelência incompleto. E é no sentido de incompletude que se insere uma modalidade de educação que faça apelo a formação permanente, em busca de uma sociedade menos estratificada, na qual os princípios éticos são almejados como condição sine qua non para que exista o mínimo de compreensão entre os seres humanos, e, para tanto, é fundamental um modelo de educação que persista durante toda a vida do indivíduo, conforme apregoa a UNESCO:

Uma educação permanente, realmente dirigida às necessidades das sociedades modernas não pode continuar a definir-se em relação a um período particular da vida _ educação de adultos, por oposição à dos jovens, 
por exemplo _ ou a uma finalidade demasiado circunscrita _ a formação profissional, distinta da formação geral. Doravante, temos de aprender durante toda a vida e uns saberes penetram e enriquecem os outros. (1998, p. 103-4)

Diante disso, A EJA se qualifica plenamente a ser a protagonista na educação integral e continuada, de forma que o adulto, na condição de educando, seja partícipe ativo deste processo, que não se deixe apenas conduzir para o mundo exterior, mas que se conduza em concomitância aos saberes adquiridos durante sua existência.

A despeito das prerrogativas documentais oficiais, é interessante se perceber que os programas de Educação de Jovens e Adultos sejam pautados por princípios que respeitem todas as características econômicas, sociais, culturais, cognitivas e afetivas do público a que estão dirigidos. Nesse sentido, é relevante entender que antes de qualquer compreensão conceitual alheia aquilo que o jovem e adulto em situação de aprendizagem está em contato, sejam levadas em consideração as idiossincrasias particulares a cada grupo social.

Logo, tomando por base Paiva (2006), em estudos realizados sobre os processos cognitivos da formação humana, são necessários entre 12 e 13 anos de estudos formais para que o indivíduo possa estar em plenas condições de letramento, as quais se considera ideais para se ter autonomia e experiência frente a realidade que se lhe apresenta cotidianamente.

É de extrema relevância que o docente consiga mostrar ao aluno da Educação de Jovens e Adultos o viés reflexivo, que deve desenvolver sobre os problemas que o atingem em um contexto sócio-econômico específico, da mesma forma que enquanto ser humano. Possibilitando que ele consiga compreender a necessidade de ser partícipe ativo nas mudanças que podem lhe atingir (SILVA, 2007).

\section{O ENSINO DE FILOSOFIA NA EJA}

No Documento-Base do PROEJA (BRASIL, 2006) é afirmado que este programa nasceu ao mesmo tempo em que foi articulada a ampliação da Rede Federal de Educação Profissional e Tecnológica. A junção da educação profissional com a EJA tem por ponto norteador a formação humana em suas concepções mais amplas, não compreendendo o indivíduo apenas como força de trabalho, ao dispor do mercado, mas como sujeito ativo na construção de sua própria vida. O citado documento afirma ipse literis que esta é uma "formação que combine, na sua prática e nos fundamentos científicos-tecnológicos e históricos sociais - trabalho, ciência e cultura - e o papel estratégico da educação profissional nas políticas e inclusão social (BRASIL, 2006,p.2).

O Decreto 5.478, de 24 de Junho de 2005 deu início ao PROEJA, e teve como alicerce a Rede Federal de Educação Profissional e Tecnológica. O viés primário foi não apenas a formação de mão de obra para diversas áreas, mas principalmente, universalizar a educação básica de qualidade.

O mote de toda a teorização em volta PROEJA é sobremaneira o desenvolvimento da cidadania. Termo este que é pivô de muitas e aprofundadas discussões. Sendo assim, é 
impossível que se entenda a concepção adotada aqui sem que se faça uma breve referência a raiz do termo cidadania que é intrinsecamente ligado a política.

$\mathrm{Na}$ atual conjuntura do mundo ocidental, fala-se constantemente sobre a valorização da cidadania como uma ferramenta para afirmar o indivíduo na coletividade que é a sociedade na qual se insere. O vocábulo cidadania expressa um conjunto de direitos que permitem às pessoas participarem ativamente da vida pública. (DALLARI, 1998).

$\mathrm{Na}$ analogia entre cidadania e política, na medida que o termo política vem do grego pólis - cidade - é razoável perceber que a cidade é uma comunidade organizada, formada pelos cidadãos livres (politikos) (PETERS, 1983). Junto com isso, podemos recorrer ao latim e, notar que polis quer dizer civitas, que originou outro termo latino civitate, de onde vem nome utilizado no português: cidade. Portanto, a cidade é compreendida como uma coisa pública e coletiva.

Unicamente porque o termo grego ta politika (PETERS, 1983)quer dizer, os interesse públicos, ou seja, os negócios que são dirigidos pelos cidadãos: os costumes, as leis, o dinheiro público, e tudo o mais que tenha relação com a comunidade. A coisa pública em latim é a res publica (O que no português costumamos chamar de República).

Para resumir, poderemos dizer que tanto pólis quanto civitas correspondem ao que conhecemos como Estado, ou conjunto das instituições públicas e, ta politika e res publica designam o que conhecemos como práticas públicas, ou a maneira de como se deve participar do coisas públicas.

Logo, ser cidadão, pela perspectiva levantada aqui é participar ativamente da condução de sua própria vida, com já mencionado anteriormente.

Contudo, diante da exposição feita, é importante trazer à baila o ponto crucial no que se refere a construção de um sentimento de cidadania, a saber: quais instrumentos ou saberes seriam os responsáveis por isso?

Por efeito dos questionamentos levantados, é razoável assinalar que posteriormente ao Decreto governamental que criou o PROEJA, mais precisamente no ano de 2008, a Lei 11.684 tornou obrigatório em todas as escolas de ensino médio o ensino das disciplinas de Filosofia e Sociologia.

\subsection{A HISTÓRIA DO ENSINO DE FILOSOFIA NO BRASIL}

Especificamente a disciplina de Filosofia já foi oferecida inicialmente pelos jesuítas na época do Brasil colônia. Tinha por base a reafirmação da autoridade da Igreja, por meio da tradição escolástica. Consequentemente, fazia parte das políticas da Contra-Reforma. Era ainda uma disciplina ministrada mormente aos membros da elite do Brasil colônia (ARANHA; MARTINS, 1998).

O ensino de Filosofia permaneceu mesmo depois que a Companhia de Jesus foi expulsa do Brasil, pelo Marquês de Pombal, ainda no século XVIII. No século XIX a disciplina de Filosofia passou a ser obrigatória no ensino médio, como uma espécie de formação propedêutica, em função do grande número dos cursos jurídicos (ARANHA; MARTINS, 1998). 
O que pode se asseverar é que em momento algum que esteve presente nos diferentes estágios da educação brasileira a disciplina de filosofia fugiu da influência religiosa. Mesmo quando obteve êxito no aspecto de afastar-se da influência religiosa, a Filosofia ainda se manteve fortemente ligada ao enciclopedismo e a erudição de cunho europeu.

Fato é que ocorreram diversos direcionamentos quanto ao destino da Filosofia no currículo do ensino básico no século passado. Houve a Reforma Francisco Campos, em 1932, que tornou obrigatório o ensino da mesma. A Reforma Capanema, 1942. Em 1961, com a Lei de Diretrizes e Bases da Educação Nacional, 4.024, a Filosofia perdeu a obrigatoriedade no ensino básico, tornando-se complementar. Porque havia o entendimento de que não correspondia as necessidades de formação de mão de obra para a industrialização do país (CORREIA, 2009).

Em 1968, a Filosofia passou a ser uma disciplina optativa e, finalmente, em 1971, com a Lei 5.692, foi excluída do currículo do ensino médio (ARANHA; MARTINS, 1998). Sobretudo pela influência dos acordos MEC-Usaid, nos quais vigorava a tecnicização do ensino, portanto, os conteúdos de Filosofia não satisfaziam às necessidades do aparato econômico-industrial vislumbrado pelas autoridades de educação brasileiras (ALVES, 1968).

As disciplinas de Educação Moral e Cívica e Organização Social e Política Brasileira, foram posta no lugar da Filosofia. Nesse sentido, é patente o viés político e ideológico que uma ação como esta carrega, na medida em que tende a solapar o caráter crítico, ou pretensamente/potencialmente criador de autonomia, que estava presente na disciplina de Filosofia, para que em seu lugar ocorresse o acomodamento da população, em função de conteúdos com cunho de disciplinamento social. Por esse prisma, Cartolano afirma a respeito da Filosofia:

Enquanto serviu à transmissão de valores aceitos por uma elite clerical e pelos católicos no poder, teve livre acesso aos horários escolares. À medida que passou a refutar as ideias desse 'humanismo' conservador e a elaborar uma teoria critica a partir dessa realidade concreta, foi relegada a segundo plano e impedida de continuar o seu empreendimento. (citada por ARANHA; MARTINS, 1998, p.80)

Independente da cambiante história da Filosofia nas escolas brasileiras, que na maior parte do tempo esteve a serviço na manutenção de interesses outros, que não a reflexão sobre a própria realidade na qual os estudantes se encontravam, o fato marcante é que quando não mais tinha serventia, e até mesmo começava a incomodar o status quo, o conteúdo de Filosofia passou ao ostracismo educacional.

\subsection{A LDB E OS CONTEÚDOS FILOSÓFICOS}

Nas décadas de 70 e 80 houveram pouquíssimos levantes, na realidade raríssimas exceções, que tivessem a pretensão de reverter a problemática da falta de conteúdo eminentemente crítico nas escolas nacionais. No entanto, em 1996, a Lei de Diretrizes e Bases da Educação Nacional, em seu artigo 36, parágrafo $1^{\circ}$, inciso III, faz uma menção aos 
conteúdos de Filosofia (e Sociologia), afirmando que o educando deveria, no final do ensino médio, apresentar "domínio dos conteúdos de Filosofia e de Sociologia necessários ao exercício da cidadania” (BRASIL, 1996, p.14).

Na realidade, conforme Aranha e Martins (2009), Correia (2009) e outros teóricos dispõem, o inciso supracitado é bastante impreciso, por não expressar de maneira compulsória os conteúdos de Filosofia e Sociologia, nem mesmo tencionou demonstrar quem deveria ministrar tais conteúdos. Logo, dá margem para um cem número de generalizações que parcamente poderiam indicar um direcionamento, a saber: que Filosofia e Sociologia estão intimamente relacionados ao desenvolvimento da cidadania.

De qualquer forma, em 2008, a Lei 11.684, aludida anteriormente, tornou obrigatório o ensino das duas disciplinas. O mote é mais uma vez aquele que iniciou a discussão, ou seja, que pode-se engrandecer a formação dos alunos, principalmente no que tange ao desenvolvimento da cidadania plena, com os conteúdos críticos-reflexivos. Tais conteúdos representam condições necessárias e suficientes, juntos com as diversas outras, dos mais variados eixos, para um formação completa do indivíduo.

Especificamente no que toca à Filosofia, é notório que os conteúdos ministrados aos alunos devem estar relacionados as suas experiências cotidianas, ressaltando o ato de fazer retroceder, ou voltar atrás, o pensamento, permitindo o questionamento daquilo que já é conhecido, facultando ao sujeito o domínio da realidade que está justaposta ao seu ser.

Cotrim e Fernandes (2010), impulsionam ainda mais a discussão rumo ao papel da Filosofia nas escolas brasileiras ao interpretarem o artigo 35 , da LDB, que estipula as quatro finalidades do ensino médio, que são:

I - a consolidação e o aprofundamento dos conhecimentos adquiridos no ensino fundamental, possibilitando o prosseguimento de estudos;

II - a preparação básica para o trabalho e a cidadania do educando, para continuar aprendendo, de modo a ser capaz de se adaptar com flexibilidade a novas condições de ocupação ou aperfeiçoamento posteriores;

III - o aprimoramento do educando como pessoa humana, incluindo a formação ética e o desenvolvimento da autonomia intelectual e do pensamento crítico;

IV - a compreensão dos fundamentos científico-tecnológicos dos processos produtivos, relacionando a teoria com a prática, no ensino de cada disciplina. (BRASIL, 1996, p.14)

Por meio da hermenêutica filosófica, constata-se que é indissociável a relação entre os conteúdos e métodos inerentes à disciplina de Filosofia, que leva a um pensar com mais rigor, e a educação em seu sentido lato, que tem por objetivo tornar a vida do indivíduo melhor. 


\subsection{REFLETINDO PARA A PRÁTICA DA LIBERDADE}

Historicamente é atestado que a Filosofia tem a prerrogativa de impactar os sujeitos, ensejando um viver melhor, trabalhando com aquilo que distingue o ser humano dos outros seres vivos, que é a capacidade racional. Aristóteles assevera, em alguns de seus textos, que o homem é um animal que possui o logos, ou seja, a capacidade de falar de uma forma sensata e de refletir sobre os seus atos (PISIER, 2004). A capacidade intelectiva do ser humano implica, por conseguinte - e sobre este ponto o autor deixa muito claro em sua obra Ética a Nicômacos (1999) - no pensar e refletir racionalmente, sendo-lhe muito própria e estando inscrita em sua essência, a tal ponto de constituir um diferencial do homem em meio às demais criaturas da natureza.

Capacidade, aqui, parece ser uma palavra chave para a questão que estamos a discutir neste ensaio, uma vez que nos remete imediatamente a outro bem, para muitos filósofos o Bem supremo, isto é, o Bem auto-suficiente e autárquico, acima de todos os demais bens estimados pelas pessoas: a liberdade. Pois é por meio da liberdade que os indivíduos têm a possibilidade de desenvolver suas capacidades segundo valores e crenças que estimam, idéia esta defendida pelo filósofo e economista detentor de um prêmio Nobel, Amartya Kumar Sen (2000), e que representa na atualidade o conceito mais aceito e difundido de desenvolvimento humano. Quando não se tem liberdade - social, econômica, política - não se pode desenvolver as capacidades que cada um julga importantes para si e que fazem parte de seu projeto autônomo e autêntico de vida; logo, não se tem desenvolvimento e, por conseguinte, não se alcança a felicidade.

A felicidade, já pregava o mesmo Aristóteles (1999), não depende de riqueza, nem de honrarias, nem de bens externos de uma maneira em geral; a grosso modo, a felicidade se atinge por meio do emprego constante da habilidade inata do ser humano de pensar e de refletir sobre suas ações, coisa que só é possível devido à autonomia, causada pela mesma capacidade intelectiva. No final das contas, tudo remete à liberdade, pelo que se tem a conviç̧ão de ser esta, e não a felicidade, o sumo Bem do homem, haja vista que a própria felicidade depende desta mesma liberdade - ao menos da liberdade de, dentro de certos limites, que nunca cessam de existir, de dirigir seus próprios pensamentos e, através deles, sua própria vida. Assim, liberdade, autonomia ou autodeterminação e capacidades são idéias estreitamente relacionadas e mutuamente reforçadoras, e a reflexão sobre esta tríade pode conduzir a um pensamento mais aprofundado acerca da possibilidade da filosofia e do ato de pensar como suportes da dignidade humana.

A forma pela qual os conteúdos de Filosofia ganham relevo, inseridos na formação de indivíduos, principalmente daqueles que são marcados por trajetórias descontínuas, como no caso dos alunos da EJA, é ao levar ao desenvolvimento amplo do acesso à cidadania. Para Pinsky, (2005) o conceito de cidadania ultrapassa os meros direitos políticos e civis, englobando, outrossim, os diretos sociais, entendidos como "aqueles que garantem a participação do indivíduo na riqueza coletiva: o direito à educação, ao trabalho, ao salário justo, à saúde, a uma velhice tranqüila." (PINSKY, 2005, p. 9). 


\section{A FILOSOFIA NA EJA IMPLICA NA CONSTRUÇÃO DA CIDADANIA}

É inegável que o conteúdo ministrado na matéria de Filosofia em qualquer modalidade de ensino está intimamente relacionado as circunstâncias sociais. Não se quer exprimir que estes sejam arrolados às ideologias econômicas e políticas dominantes, mas que devem ter toda a precaução de revelar ao discente a conjuntura na qual a sociedade em que vive está abalizada, para que seja permitido ao aluno contemplar e ser membro ativo da sociedade. Portanto, ao discente deve ser disponibilizada a estrutura teórica dos valores, crenças e fazeres que perpassam sua vida. Facultando a ele, sobretudo, a inserção a cidadania plena.

A despeito do que foi apontado no parágrafo precedente, é lícito pensar que aos olhos da contemporaneidade a cidadania pode aparentar ser algo corriqueiro e natural, fato que não corresponde exatamente a realidade. É mais correto asseverar que é uma ocorrência puramente social e, portanto, artificial, ou seja, criada pelo homem. A conclusão é que entendimento do que vem a ser cidadania tem passado por diversas acepções ao longo da história, não implicando em um conceito inflexível, mas extremamente dinâmico e volátil, adequando-se ao contexto social, político e cultural vigente. Nas palavras de Pinsky, "cidadania não é um conceito estanque, mas um conceito histórico, o que significa que seu sentido varia no tempo e no espaço." (PINSKY, 2005, p. 9).

Provavelmente o maior problema encontrado no ensino de Filosofia para o alunado da EJA seja o desenvolvimento de uma metodologia própria para o conteúdo apresentado, haja vista que o grande empecilho com o qual se deparam tanto o docente, quanto o discente, é a deficiência apresentada por ambas as partes. Por um lado a falta de habilidade na própria formação docente, quanto ao domínio de técnicas pedagógicas que facilitem a aprendizagem do conteúdo pelo aluno, por outro, o déficit de aprendizagem apresentado pelo aluno, em função da descontinuidade do processo de cooptação de conhecimentos. Gerando uma dificuldade quanto a compreensão dos conteúdos eminentemente abstratos abordados pela Filosofia.

Nesse sentido, coube uma análise das condições da disciplina de Filosofia em um exíguo corpo amostral, de modo que se pudesse compreender as distintas demandas e expectativas do alunado. Assim como, orientar o fazer docente no que tange as práticas pedagógicas mais harmonizadas a realidade da EJA.

\subsection{FILOSOFIA: PERCEPÇÕES E EXPECTATIVAS NA CONTEMPORANEIDADE}

No caso específico hora levantado, os discentes da modalidade, do Instituto Federal de Educação, Ciência e Tecnologia do Rio Grande do Norte, campus Macau, dos cursos Técnico Nível Médio Integrado EJA em Química e Técnico Nível Médio Integrado EJA em Recursos Pesqueiros, foram interpelados, por meio de um questionário com perguntas fechadas. No qual eram levantadas questões diversas sobre o ensino da disciplina de Filosofia, assim como sobre a percepção dos alunos sobre a matéria.

No período de 02 a 05 de abril de 2011, no Centro de Tecnologia de Recursos Pesqueiros, no campus Macau do IFRN, responderam ao questionário de pesquisa 79 alunos, de um total de 139 , o que perfaz uma percentual em torno de $57 \%$. Após contabilização das 
respostas oferecidas pelos sujeitos participantes, estabelecemos apreciação de resultados à luz do diálogo entre os teóricos, que fundamentam esta pesquisa, e a nossa prática como docente da disciplina Filosofia na modalidade de EJA.

Como está posto, os participantes são alunos do IFRN, campus Macau. Referência em educação no âmbito nacional, essa agência escolar empírica tem gerado um quadro de qualificação, de natureza profissional e humanística, que certamente pouco a pouco está contribuindo para o crescimento socioeconômico da microrregião salineira.

Dos estudantes entrevistados, $29 \%$ dos afirmaram que estudar Filosofia representa uma dificuldade para eles, na medida em que pensar abstratamente não é algo com o qual estejam habituados. O que leva a entender, de acordo com os outros $71 \%$, não existe, ou é minimizada a dificuldade elencada. Mesmo que uma parcela significativa tenha demonstrado dificuldade de lidar com conteúdos filosóficos, todos os respondentes afirmaram que pensar com rigor é fundamental para o desenvolvimento humano e profissional, inclusive, para a titulação técnica que obterão ao final do curso. Por conseguinte, observa-se que o alunado tem um mínimo de consciência quanto ao valor da disciplina de Filosofia no seu desenvolvimento pessoal e profissional, sobretudo, no que tange à forma sistematizada de pensar sobre a própria percepção humana. Na medida em que "o pensamento é o material da Filosofia. A Filosofia é o pensamento que sabe a si mesmo para além da evidência de que se pensa" (TIBURI, 2008). Esse é o entendimento, mesmo que intuitivo, sem que ocorra consciência do discente EJA, quanto a indispensabilidade da reflexão impulsionada pelo conteúdo de ordem filosófica.

Quase a totalidade dos entrevistados (96\%) acredita que não pode haver uma seç̧ão entre teoria e prática. Pensamento (teoria) e ação (prática) se alinham perfeitamente. Definise teoria como o ato de observar, ver, examinar, oferecendo ao sujeito a condição de contemplar a realidade que o circunda. Ao passo que prática é o avivamento, por meio do qual a teoria toma parte da experiência vivida. Fica subtendido que a técnica é um conjunto de saberes articulados para obter um resultado qualquer. Porquanto, o ser humano está continuamente subordinado ao ambiente e aos desafios apresentados na conjuntura ambiental. Por isso, o homem se encontra em toda a cotidianidade com a técnica, sendo produtor desta, não apenas subserviente, como corriqueiramente se imagina.

Ao humanizar-se o homem se entrega a sua finitude, enquanto um projeto sempre inacabado, sobre o qual o imperar da técnica o é apenas enquanto participação, não como submissão ou dominação. Só assim é possível ao homem lançar-se efetivamente em sua finitude, só quando percebe claramente que está além de seu poder determinar sua existência, e nessa posição, da técnica que cerceia aquela. Está em seu poder dispor de como vai se relacionar com o mundo, e do que está imediatamente a sua volta, que o cerca e cerceia.

Essa é a condição de humanização do homem. Sendo assim, é inferido que o fazer educacional ao qual o aluno está sujeitado, deve conduzi-lo a criação de liberdades essenciais conducentes de sua vida. Tal acepção se associa a percepção que os filósofos estóicos tinham da liberdade, enquanto eleutheria, denotando efetividade do pensamento na ação (ARRIANO, 2007). Nessa proposta, a liberdade é criada e recriada de maneira constante e efetiva durante 
todo o percurso da existência do sujeito. Nomeadamente, no caso da EJA, o indivíduo é levado a se encontrar com a construção dessa prática de liberdade, por força da reflexão facultada e sistematizada pela prática de filosófica.

Platão (1996), em sua famosa Alegoria da Caverna, presente no Livro VII de $A$ República, mostra-nos o valor do autoconhecimento, ao discorrer sobre a possibilidade de vivermos enganados, como se estivéssemos presos no fundo de uma caverna, totalmente determinados pelas sensações. Poderíamos considerar que para ele aquele que "saiu da caverna" é menos coagido por determinações externas e torna-se mais senhor de si, responsável por usar o crivo do intelecto na deliberação acerca de sua compreensão de vida e, de certa forma, vindo a perceber que a reflexão é a causa principal da liberdade. Logo, para aquele que visa a verdadeira liberdade, a afecção que o atinge não consegue ser maior do que o autoconhecimento que o permite ser livre. Ou seja, não significa que não experimente afecções desagradáveis, apenas que estas causam-lhe menos impacto, pois as reconhece como sendo independentes de sua vontade.

A consciência dessa independência permite que o ser humano perceba que nunca está pronto, que está em frequente mudança, por força da dinamicidade da própria existência (CORTELLA, 2006). É essa a realidade que deve ser criada para o aluno da EJA, de forma que apreenda o universo que pode se abrir a sua frente, em função de uma educação reflexiva, que não o deixe estagnado. O conforto, entendido nesse momento como passividade, não deve superestimado, já que não ajuda o indivíduo a vislumbrar alternativas outras que não aquelas com as quais está habituado, pois o leva a um estado de "redundância afetiva e na indigência intelectual" (CORTELLA, 2006, p.11).

O grande desafio imposto na interação com os alunos da EJA é acabar com o sentimento de término, de satisfação (CORTELLA, 2006), de ter percorrido todo o caminho no que tange a formação humana. Fato que encerra uma problemática difícil de ser combatida, a saber, faz com que o sujeito não tenha mais motivações intrínsecas a buscar novos horizontes. Cabe ressaltar que, nessa situação, o papel do professor de Filosofia é de incitar o desejo por um tipo de conhecimento que não é alheio a vida do aluno, mas que lhe é apenas inusitado, por não ter tido oportunidade de entender a cultura, o trabalho, a sociedade, a técnica e a tecnologia com o rigor do olhar filosófico. Um olhar de espanto continuo, que não pode se abreviar por buscas de respostas precipitadas. Um olhar que não banaliza os fatos que a realidade oferece insistentemente.

Como se observou, o aluno da EJA, respondeu, mesmo sem ter pensado profusamente, que $o$ ato de refletir é relevante a sua formação humana e profissional. A leitura de mundo que faz, na medida em que procura dar significados, o predispõe a se perceber como um ser ainda incompleto, em busca de construir uma realidade pessoal e, portanto, social distinta daquela a qual está imerso.

Para tanto, é importante que o aluno da EJA seja defrontado com metodologias de ensino que ultrapassem as barreiras ortodoxas do ensino de Filosofia. Exemplarmente, a oralidade, as grandes elucubrações temáticas, consubstanciadas em toda a história do ensino de Filosofia, é o de somenos predominância, ao se considerar a dinamicidade e apreensão dos 
conteúdos abordados, com $19 \%$ das preferências. Já a leitura de textos $(30,4 \%)$, e as videoaulas $(50,6 \%)$, são os considerados mais adequados ao entendimento dos temas levantados pela Filosofia. A razão disso é provavelmente porque o leitura de cunho filosófico "encontraria sua alegria de ser em colocar-se como mote de uma aventura do pensar que nele são se acaba.[...] Eles fazem pensar, levam a pensamentos que não estão contidos ou em germe neles se ocultam"(TIBURI, 2008, p.110). A leitura extrapola necessariamente a esfera da interpretação da escrita, se resguardando em sua acepção etimológica, que significa recolher, escolher, captar com os olhos. Portanto, o estudante da EJA optar por visualizar aquilo que $o$ atinge teoricamente.

Se entende que o professor de Filosofia para a modalidade EJA deve centrar seus esforços em atingir de maneira franca o seu alunado. Atingindo-o faz com que este último não se resigne frente a sociedade e as intempéries existenciais. Por fim, contribui igualmente para a constituição do sujeito na consumação de sua cidadania.

\section{CONSIDERAÇÕES FINAIS}

O trabalho apresentado pretendeu em um primeiro capítulo elencar historicamente todas as fases por que passou a Educação de Jovens e Adultos no Brasil. Para isso fez um breve levantamento das políticas governamentais que incidiram sobre educação popular de Jovens e Adultos, inclusive sobre a prerrogativa que estas tiveram, em um certo momento, de formar para o mercado. Em seguida apontou o caminho adotado pela educação brasileira rumo a democratização do país, fundamentado em teóricos como Anísio Teixeira e Paulo Freire. Nesse aspecto, mostrou-se que a educação democrática tomou por mote o desenvolvimento da cidadania, os quais também são apontados na declaração de Hamburgo. Foram elencados os números da educação brasileira em relação ao público que está na faixa etária da EJA. Por último, o capítulo inicial visualizou o PROEJA e os objetivos principais deste, sobretudo no que tange a uma formação integral e continuada do sujeito.

O capítulo subsequente teve a ambição de traçar os caminhos percorridos pela disciplina de Filosofia até a sua materialização na EJA. Arrolado a isso, foi mencionado que as disposições iniciais do documento base do PROEJA objetivam a construção de conceitos que são caros à Filosofia, como: trabalho, ciência e cultura. Destarte, a EJA tem por fim não apenas a profissionalização dos alunos, mas, principalmente, a formação da cidadania. De pronto, entende-se que o teor da Filosofia tem especial relevância na transformação de consciências para a efetiva prática da liberdade e da autonomia.

No capítulo final objetivou-se fazer uma relação ampla entre a formação proposta pela disciplina de Filosofia e o desenvolvimento da cidadania, uma vez que os conteúdos desta perpassam todas as instâncias da vida dos indivíduos. Foi necessitado que se mostrasse que a cidadania é uma construção histórica, ou seja, que os indivíduos tem papel preponderante na efetivação desta. Sobremaneira quando realizam que a reflexão é motor do desenvolvimento social. Desta maneira, foram levantadas as percepções que o aluno da EJA têm quanto a Filosofia, para que assim, o fazer pedagógico do docente se cruze aquilo que convém aos discentes. Ponderou-se que a Filosofia, na EJA, deve está voltada eminentemente para levar a 
inquietude. Para isso, os professores devem se preocupar com metodologias que contemplem a situação de vida do aprendente de forma ampla.

Certamente o trabalho elaborado aqui não deu conta de todas as variantes que estão implícitas na oferta da disciplina de Filosofia para o alunado da EJA. Teve a pretensão de levantar, mesmo que minimamente, alguns questionamentos sobre a história tanto da Educação de Jovens e Adultos quanto do ensino de Filosofia no Brasil. Como possibilidades futuras, as reflexões levantadas aqui, pretendem levar a labores outros que opinem de forma ainda mais rigorosa sobre alguns temas corriqueiros na formação humana, tais como: humanização, técnica, cidadania, autonomia e liberdade.

\section{REFERÊNCIAS BIBLIOGRÁFICAS}

1. ALVES, M. M. Beabá dos MEC-Usaid. Rio de Janeiro: Edições Gernasa, 1968.

2. ARANHA, M. L. de A.; MARTINS, M. H. P. Temas de filosofia. 2.ed. São Paulo: Moderna, 1998.

3. Filosofando: introdução à Filosofia. 4.ed. São Paulo: Moderna, 2009.

4. ARISTÓTELES. Ética a Nicômacos. Tradução Mário da Gama Kury. 3. ed. Brasília: Universidade de Brasília, 1999.

5. ARRIANO, F. O manual de Epicteto: aforismos de sabedoria estóica. Tradução a partir do grego clássico e notas de Aldo Dinucci. São Cristovão: Universidade Federal de Sergipe, 2007.

6. ARROYO, M. G. Educação de Jovens-adultos: um campo de direitos e de responsabilidade pública. IN: SOARES, L.;GIOVANETTI, M. A. e GOMES, N. (orgs.) Diálogos na educação de jovens e adultos. 2.ed. Belo Horizonte: Autentica, 2007.

7. BRASIL. Ministério da Educação. Lei de Diretrizes e Bases da Educação Nacional. Brasília, 1996.

8. - Programa Nacional de Integração da Educação Profissional com a Educação Básica na Modalidade de Educação de Jovens e Adultos. Brasília, 2007.

9. . Parecer CNE/CEB 11/2000. Brasília, 2000.

10. _. Programa da Integração Profissional do Ensino Médio na Modalidade de Jovens e Adultos: documento base. Brasília, 2006.

11. Ministério da Educação/Fundação Joaquim Nabuco. Manifesto dos pioneiros da educação nova (1932)e dos educadores (1959). Recife: Editora Massangana, 2010.

12. _. IBGE. Síntese de indicadores sociais 2010: uma análise das condições de vida da população brasileira. Rio de Janeiro, 2010.

13. IB IBEE. Pesquisa Nacional por Amostra de Domicílios. Brasília, 2010.

14. CELLARD, A. A análise documental. In: POUPART, J. et al. A pesquisa qualitativa: enfoques epistemológicos e metodológicos. Petrópolis, Vozes, 2008.

15. CHAUÍ, M. Iniciação à Filosofia. São Paulo: Ática, 2011.

16. CORREIA, W. Filosofia, educação básica e cidadania. Revista Espaço Acadêmico. Disponível em: <<http://www.espacoacademico.com.br/092/92correia.htm > Acesso em: 10 Jun. 2011.

17. CORTELA, M.S. Não nascemos prontos! provocações filosóficas. Petrópolis,RJ: Vozes, 2006. 
18. COTRIM, G.; FERNANDES, M. Fundamentos de Filosofia. São Paulo: Saraiva, 2010.

19. DALLARI, D.de A. Direitos humanos e cidadania. São Paulo: Moderna, 1998.

20. FREIRE, P. Educação como prática da liberdade. 27. ed. Rio de Janeiro: Paz e Terra, 2003.

21. PINSKY, Jaime; PINSKY, Carla Bassanezi (Orgs). História da cidadania. 3.ed. São Paulo: Contexto, 2005.

22. PAIVA, V.P. História da educação popular no Brasil: educação popular e educação de adultos. 6.ed. São Paulo: Loyola, 2003.

23. PAIVA, J. Educação de jovens e adultos: direitos, concepções e sentidos. Niterói: Universidade Federal Fluminense. Tese de doutorado - Faculdade de Educação Universidade Federal Fluminense, 2005.

24. PETERS, F.E. Termos filosóficos gregos: um léxico histórico. Prefácio Miguel Baptista Pereira; Tradução Beatriz Rodrigues Barbosa. 2. ed. Lisboa: Calouste Gulbenkian, 1983.

25. PISIER, E. História das idéias políticas. Tradução Maria Alice F. C. Antônio. São Paulo: Manole, 2004

26. PLATÃO. A República. Introdução, tradução e notas Maria Helena da Rocha Pereira. 8. ed. Lisboa: Fundação Calouste Gulbenkian, 1996.

27. SEN, A.K. Desenvolvimento como liberdade. Tradução Laura Teixeira Motta. 4. reimp. São Paulo: Companhia das Letras, 2000.

28. SILVA, Solange Aparecida. Educação de jovens e adultos: um confronto entre teoria e prática na construção da cidadania. Monografia de conclusão de curso - Faculdade de Ciências - Campus Bauru - Universidade Estadual Paulista Julio de Mesquita Filho, 2007.

29. TEIXEIRA, A. Educação é um direito. 2. ed. Rio de Janeiro: Editora UFRJ, 1996.

30. TIBURI, M. Filosofia em comum: para ler-junto. Rio de Janeiro: Record, 2008.

31. UNESCO. Conferência internacional sobre educação de adultos: Declaração de Hamburgo. Brasília: SESI/UNESCO, 1999.

32. __ Educação: um tesouro a descobrir. Tradução de José Carlos Eufrázio. Brasília: Unesco; São Paulo: Cortez Editora, 1998. 